\title{
ACARDIAC ACEPHALIC TWIN GESTATION
}

M. Siva Sridhar ${ }^{1}$, D. Sai Raghavendra², D. Sowjanya ${ }^{3}$

\section{HOW TO CITE THIS ARTICLE:}

M. Siva Sridhar, D. Sai Raghavendra, D. Sowjanya. “Acardiac Acephalic Twin Gestation”. Journal of Evolution of Medical and Dental Sciences 2014; Vol. 3, Issue 29, July 21; Page: 8259-8262,

DOI: $10.14260 /$ jemds/2014/3040

ABSTRACT: Acardiac fetus is a rare lethal fetopathy encountered in monozygous pregnancies. It is a rare anomaly in which one twin has an absent, rudimentary or non-functioning heart. Ultrasound prenatal diagnosis has enabled an increasing number of observations. The spontaneous prognosis for the healthy twin is unfavorable in half of the cases.

KEYWORDS: Acardiac Acephalic Twin, TRAP Twin, Acardiac Monster, Monozygotic Twins.

INTRODUCTION: Acardiac Acephalic twin occurs as a rare phenomenon in monochorionic pregnancies with an incidence of one in 35,000 births. 9 Twin Reversed Arterial Perfusion has been recognized as necessary for development of the perfused fetus. Twin pregnancy with acardiac results from an artery-to-artery placental anastomosis in which the pump twin, morphologically normal, perfuses the abnormal acardiac twin in a reversed circulation. Clinical management depends on the spontaneous development of the acardiac fetus and the deleterious consequences for the healthy twin resulting from heart failure, anasarca or prematurity.

CASE HISTORY: A twenty two years old female came for routine antenatal checkup at tenth week gestation. A routine ultrasound done at that time revealed normal intrauterine pregnancy with no detectable anomalies. A follow up scan was done at twenty two weeks of gestation which revealed Monochorionic Monoamniotic twin gestation. The first foetus is corresponding to twenty two weeks of gestation with no congenital anomalies.

The second twin is seen with absent head, upper torso and upper limbs. No cardiac activity could be recorded. However the femur is corresponding to twenty two weeks of gestation. Solid cystic mixed echogenic subcutaneous soft tissue mass was seen encircling the abdomen and pelvis.

Till this stage the foetal growth by femur length is corresponding to the menstrual age. Screening MRI done for better evaluation of anomalies. MRI revealed Monochorionic Monoamniotic twin gestation with normal cord to the donor twin and a short cord to the recipient twin. Subcutaneous T1 hypointense, T2 mixed intense solid cystic tissue seen encircling the lower body. The recipient foetal head, thorax, upper limbs could not be seen.

No anomalies could be seen in donor twin Patients and their relatives are counseled about this rare anomaly and advised to go to higher centre for umbilical cord embolization or radiofrequency ablation. Due to their financial constraints they decided against it and opted to continue pregnancy. She was followed at regular short intervals and serial follow up scans were done for every two weeks till twenty eighth week of gestation. The foetal growth by femoral length is corresponding to menstrual age in all these scans in both the twins.

No signs of cardiac failure seen in the donor twin At twenty nine weeks of gestation patient presented with decreased foetal movements and taken up for review scan which revealed intrauterine death of donor twin Subsequently she was induced and delivered both the twins Patient denied autopsy. 
The acardiac twin weighed 900 grams with absent head, chest and upper limbs. The lower abdomen and lower limbs appear normal.

DISCUSSION: Acardiac syndrome is a rare complication of multi-foetal gestation occurring one in 35, 000 births. ${ }^{1}$ Though it can occur in dizygotic gestation most commonly seen in monozygotic twinning. Placental vascular anastomosis, artery to artery is the essential underlying factor resulting in recipient and donor twins. The recipient twin develops severe anomalies often referred to as acardia, incompatible with life.

The donor twin though devoid of anomalies may develop cardiac failure with mortality rate of 50-75\%. Though Acardius is common manifestation in all recipient twins, it has been categorized into four groups. ${ }^{1}$

In Acardiac Acephalic twin, the commonest type, head, upper torso and upper limbs are absent. The lower limbs, genitalia abdominal viscera are well preserved. In Acardius Acormus twin, only the foetal head is well developed and rest all are absent.

In Acardius Amorphous twin, there is an amorphous mass of bone, muscle, fat and connective tissue structures. In Acardius Anceps twin, the most developed type, rudimentary cranial structures with otherwise persistent trunk, limbs and organs noted. Several theories are put forward to explain this syndrome; the most common explanation is that the primary event is an arterial anastomosis ${ }^{2}$ with reversal of flow from normal to abnormal twin. ${ }^{3}$ In such a recipient twin, reduced oxygen tension results in mal-development of heart, upper torso and upper limbs. ${ }^{3}$

The other explanation says that the primary event is a mal-developed foetal heart resulting in secondary arterial anastomosis for survival of recipient twin.

Another theory says that the entire event is a chromosomal abnormality in acardiac twin.

On ultrasound the striking feature is the acardiac twin with marked edema of subcutaneous soft tissues with cystic changes in the upper portion.

The commonest sonographic signs are:

1. Monozygotic twin gestation.

2. Biometric discordance between twins.

3. Diffuse subcutaneous edema and or morphological abnormalities in the twin.

4. Absent cardiac activity.

In over $50 \%$ of cases a two vessel cord is observed in the recipient twin and signs of cardiac failure in the donor twin. The cord in acardiac twin is often short with flow reversal in the umbilical cords.

In-utero invasive treatment should be considered only in cases in which poor prognostic factors are detected, including the development of polyhydramnios, ultrasound markers of cardiac insufficiency (i.e., tricuspid regurgitation, pulsatile umbilical vein and abnormal ductus venosus wave forms in the pump twin's circulation), and large acardiac twin with rapid growth.

Therapeutic options targeted at interrupting the vascular anastomosis between the twins under ultrasound guidance. Several different techniques have been used to treat TRAP sequence by interrupting the connection between the acardiac twin and the pump twin to increase the chances that the pump twin will survive.

These techniques include cord occlusion by embolization, ligation, laser photo- coagulation, 
monopolar and bipolar diathermy 4 . Intra-fetal ablation has also been performed by alcohol injection, monopolar diathermy, interstitial laser, and radiofrequency ablation.

Utilizing RFA to treat TRAP sequence has been shown to be extremely effective. Success rate is of greater than $90 \%$ survival of the normal twin with an average gestational age at delivery of 35 weeks.

Fig. 1: Ultrasound image of Monochorionic (white arrow) Monoamniotic twin gestation Pelvis and lower limbs of normal twin $(*)$ and subcutaneous soft tissue surrounding the trunk of the pump twin (black arrow).

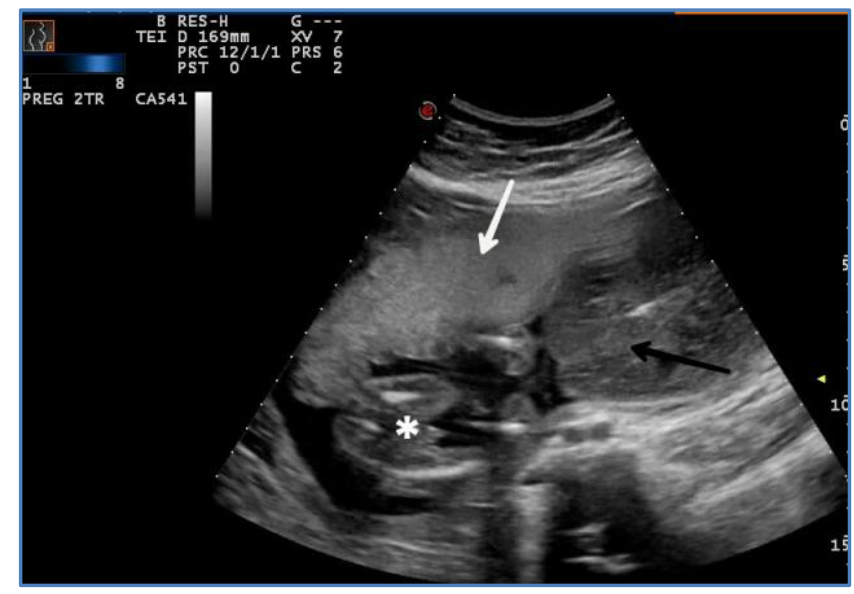

Figure 1

Fig. 2: Coronal field echo sequence Monochorionic Monoamniotic twin gestation with Donor $\left.{ }^{*}\right)$ and pump twin (black arrow) with absent head, upper torso and upper limbs.

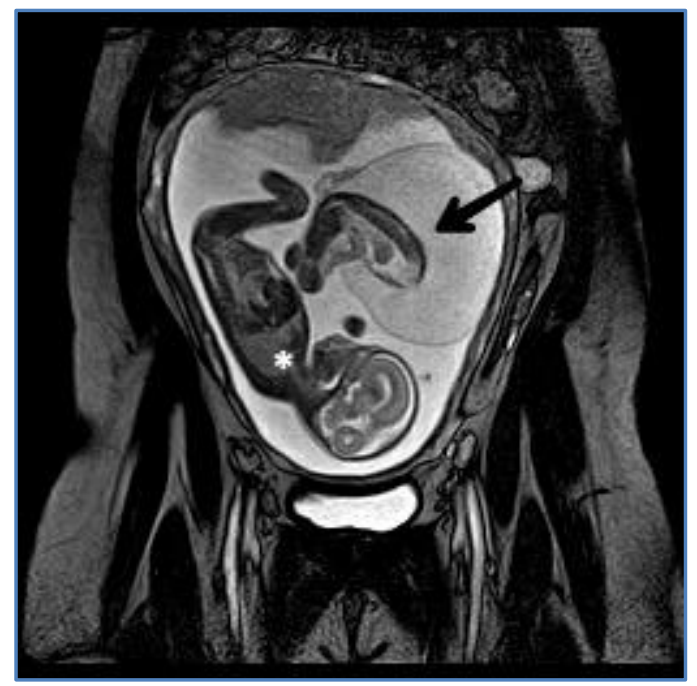

Figure 2 


\section{CASE REPORT}

Fig. 3: Coronal field echo sequence Monochorionic Monoamniotic twin gestation Donor twin $\left(^{*}\right)$ and its long cord (Black arrows).The short cord of pump twin is not readily made out.

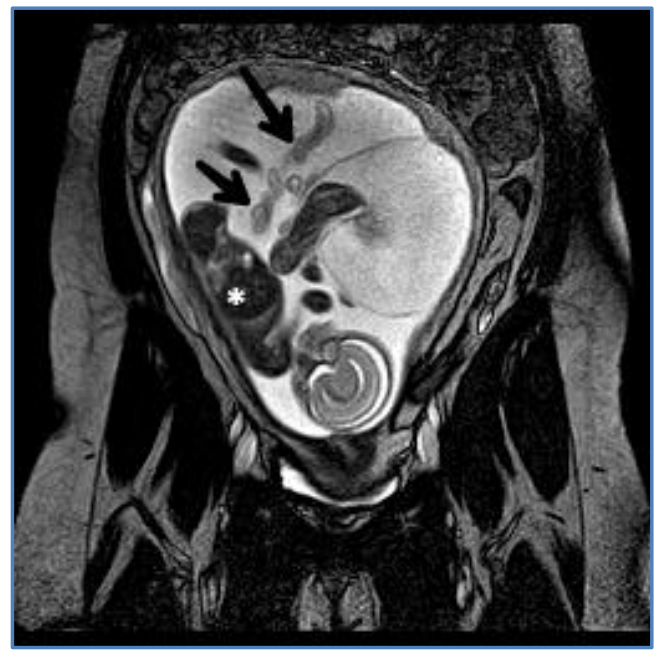

Figure 3

\section{REFERENCES:}

1. Chandramouly and Namitha. Case Series TRAP sequence. Indian J Radiol Imaging. Feb 2009; 19 (1): 81- 83. doi: 10.4103/0971-3026.45352 M..

2. Wegrzyn P, Borowski D, Nowacka E, Bomba-Opoń D, Kosińska-Kaczyńska K, KociszewskaNajman B, Wielgoś M. Interstitial laser coagulation in Twin Reversed Arterial Perfusion sequence. Ginekol pol; 2012 Nov; 83(11):865-870.

3. Hartge DR1, Weichert J. Prenatal diagnosis and outcome of multiple pregnancies with reversed arterial perfusion (TRAP-sequence). Arch Gynecol Obstet. 2012 Jul; 286 (1): 81-8.

4. Prasad RH1, Prasad TR, Kumar KD. TRAP Sequence - An Interesting Entity in Twins. J Clin Imaging Sci. 2012; 2: 56. doi: 10.4103/2156-7514.100997. Epub 2012 Sep 25.

\section{AUTHORS:}

1. M. Siva Sridhar

2. D. Sai Raghavendra

3. D. Sowjanya

\section{PARTICULARS OF CONTRIBUTORS:}

1. Associate Professor, Department of Radiodiagnosis, Andhra Medical College.

2. Post Graduate, Department of Radiodiagnosis, Andhra Medical College.

3. Post Graduate, Department of Radiodiagnosis, Andhra Medical College.

\section{NAME ADDRESS EMAIL ID OF THE CORRESPONDING AUTHOR:}

Dr. M. Siva Sridhar,

Flat No. 202,

Orchid Apartments,

Oceanview Layout,

Visakhapatnam-530003,

Andhra Pradesh.

Email: drsridharkgh@gmail.com

Date of Submission: 15/06/2014.

Date of Peer Review: 16/06/2014.

Date of Acceptance: 30/06/2014.

Date of Publishing: 19/07/2014. 